\title{
Catalytic Solvolytic and Hydrolytic Degradation of Toxic Methyl Paraoxon with La(catecholate)-Functionalized Porous Organic Polymers
}

\author{
Ryan K. Totten, Mitchell H. Weston, Jin Kuen Park, Omar K. Farha,* Joseph T. Hupp,* \\ and SonBinh T. Nguyen*
}

Department of Chemistry and the International Institute for Nanotechnology, Northwestern University, 2145 Sheridan Road, Evanston, Illinois 60208-3113, United States

\section{Supporting Information}

ABSTRACT: Two robust catechol-functionalized porous organic polymers (catPOPs) with different $T_{\mathrm{d}}$-directing nodes were synthesized using a cobalt-catalyzed acetylene trimerization (CCAT) strategy. Postsynthesis metallation was readily carried out with $\mathrm{La}(\mathrm{acac})_{3}$ to afford catalytically active Lafunctionalized catPOPs for the solvolytic and hydrolytic degradation of the toxic organophosphate compound methyl paraoxon, a simulant for nerve agents.

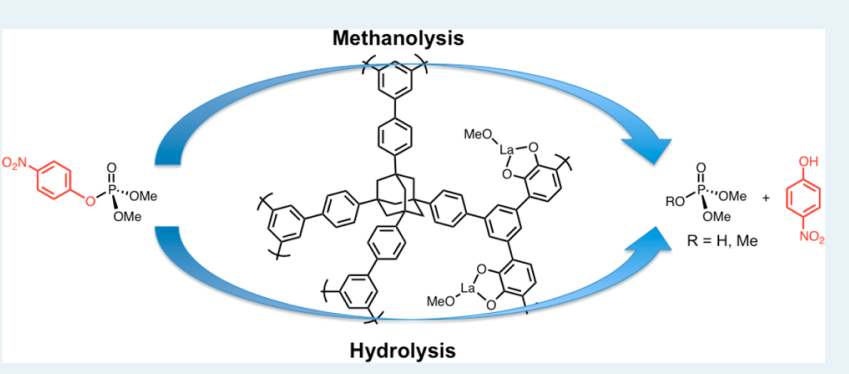

Hydrolysis

KEYWORDS: porous organic polymers, catechol, catalysis, organophosphates, lanthanum

\section{INTRODUCTION}

Over the past decade, porous organic polymers (POPs) have emerged as a new class of materials with promising applications in gas storage, ${ }^{1-7}$ chemical separation, ${ }^{3,8-11}$ and heterogeneous catalysis. $^{12-17}$ The directed assembly of one or more rigid organic building blocks into a microporous network using stable organic bonds can afford chemically and thermally stable materials with both highly accessible internal surface areas and a wide range of chemical functionalities. ${ }^{7}$ Of particular interest to us is the design of POPs suitable for applications that combine molecular recognition and catalysis. Specifically, the integration of coordinatively unsaturated metal ions into POPs should afford micropore environments that are capable of binding and transforming small-molecule substrates. ${ }^{17}$ Together with the known ability of nanometer-sized cavities to sequester reactants and enhance their in-pore concentrations beyond that in solution, ${ }^{18,19}$ this should lead to enhanced catalysis.

While metal ions have been incorporated into POPs possessing bipyridyl ligands and used for catalysis, ${ }^{16,20}$ this strategy necessitates the use of charge-compensating anions, which can fill valuable pore volumes and block coordination sites. ${ }^{12,13,15,16}$ To generate POPs that can stabilize metal ions featuring high degrees of unsaturation, we have focused instead on the use of negatively charged ligands as building blocks. In addition to porphyrin-based systems, ${ }^{13}$ we have been able to integrate catechol-bearing building blocks into POPs and successfully form POP-stabilized monocatecholated metal complexes with a series of divalent metals $\left(\mathrm{Cu}^{\mathrm{II}}, \mathrm{Mg}^{\mathrm{II}}, \mathrm{Mn}^{\mathrm{II}}\right.$, and $\mathrm{Zn}^{\mathrm{II}}$ ) that demonstrate enhanced hydrogen sorption capabilities $^{21}$ and removal of toxic chemicals. ${ }^{22}$ The dianionic catecholate ligands offset the cationic charges of divalent metal ions while their isolation inside the POP micropore precludes the formation of stable bis- and tris-chelation motifs that are the dominant species in a homogeneous environment. ${ }^{23}$ The result is metal centers with empty or labile coordination environments (solvents or water) that can be used to bind and recognize small molecules.

Given our interest in the solvolytic degradation of phosphate triesters and its relevance in the decomposition of toxic organophosphate-based nerve agents, ${ }^{19,24}$ we reasoned that a Lewis-acidic metal ion bound inside a catechol-functionalized POP would be a potent, reusable catalyst for these reactions. ${ }^{25,26}$ While both $\mathrm{Al}^{\mathrm{III}}$ and $\mathrm{Zn}^{\mathrm{II}}$ complexes have been used in the supramolecularly catalyzed methanolysis of phosphate esters, ${ }^{19,24}$ we choose to incorporate $\mathrm{La}^{\mathrm{III}}$ ions into our catechol POPs (catPOP) given its strong oxophilic nature and its ability to coordinate up to 9 ligands. ${ }^{27} \mathrm{We}$ hypothesized that (monocatecholate)La moieties stabilized inside a POP cavity would be able to bind phosphate triesters together with a large number of hydroxylated reagents, such as methanol and water, inside a micropore and accelerate its solvolytic decomposition. In addition to the dianionic catecholate ligand, the third anionic ligand of the $\mathrm{La}^{\mathrm{III}}$ ion (i.e., $\mathrm{MeO}^{-}$or $\mathrm{HO}^{-}$) or other protonated ligands $\left(\mathrm{MeOH}\right.$ or $\left.\mathrm{H}_{2} \mathrm{O}\right)$ can serve as a pool of nucleophiles in the solvolysis/hydrolysis of the coordinated phosphate ester. We note that the high activity of La ${ }^{\mathrm{III}}$ ion in the hydrolytic cleavage of $\mathrm{DNA}^{28}$ and solvolysis of phosphate triesters, ${ }^{29-31}$ has been demonstrated.

Received: March 4, 2013

Revised: April 7, 2013

Published: April 15, 2013 
Scheme 1. Synthesis of Catechol-Containing POPs $A_{2} B_{1}$ and $A_{2} C_{1}$ Using a Cobalt-Catalyzed Acetylene Trimerization Strategy (CCAT) and Their Subsequent Metallation with $\mathrm{La}^{\mathrm{III}} \mathrm{Ions}^{a}$

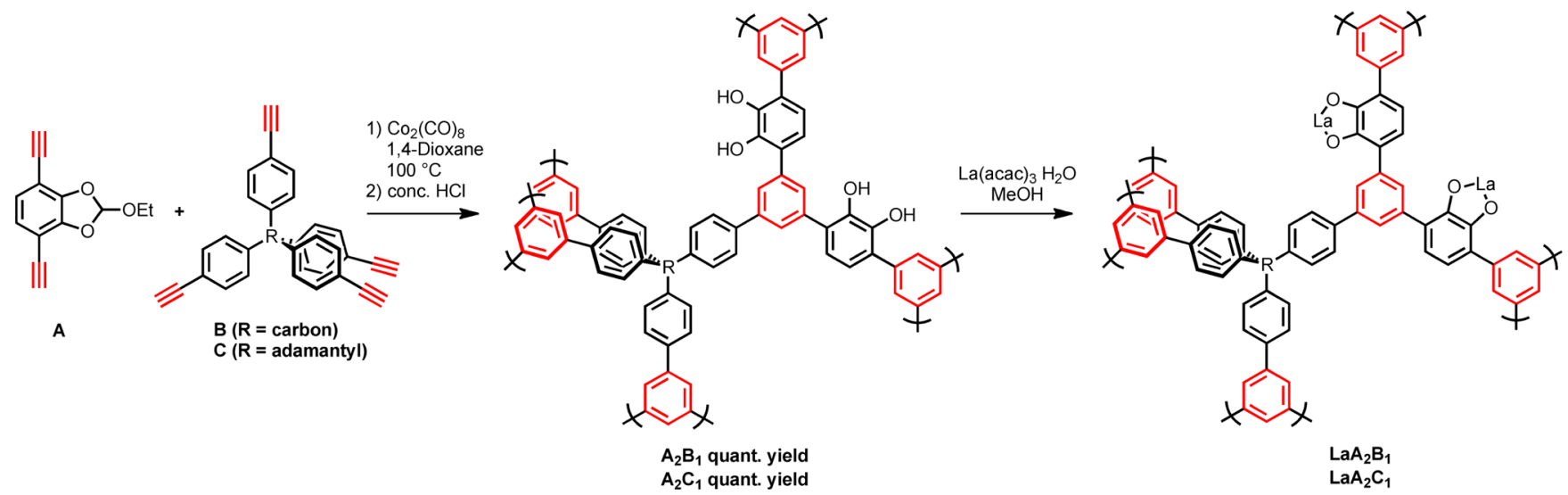

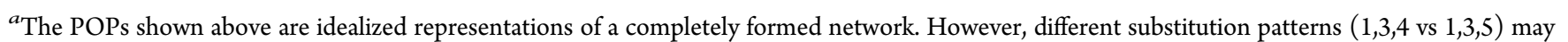
be present as well as olefins/dienes and unreacted acetylene groups because of incomplete polymerization. For the $\mathbf{A}_{2} \mathbf{B}_{1}$ composition, solid-state ${ }^{13} \mathrm{C}$ NMR analysis suggested that this material is free of olefin/diene groups. See the Supporting Information by Weston et al. ${ }^{21}$ for additional discussion.

\section{EXPERIMENTAL SECTION}

Synthesis of Polymers. POP $\mathbf{A}_{2} \mathbf{B}_{1}$ was synthesized following a previously reported procedure. ${ }^{21}$

POP $A_{2} C_{1}$. In a nitrogen-filled glovebox, a $5 \mathrm{~mL}$ microwave vial (capacity designates the amount of solution that can be safely loaded) equipped with a magnetic stir bar was charged with monomers $\mathrm{A}^{32}$ (38 mg, $0.18 \mathrm{mmol}$ ) and $\mathbf{C}^{33}$ (54 mg, 0.09 $\mathrm{mmol})$ in the same optimal ratio found for $\mathbf{A}_{2} \mathbf{B}_{1} \cdot{ }^{21}$ This mixture was dissolved in dry 1,4-dioxane (4 mL) and $\mathrm{Co}_{2}(\mathrm{CO})_{8}(30 \mathrm{mg}, 0.09 \mathrm{mmol})$ was added. The solution was stirred for $5 \mathrm{~min}$ prior to being sealed and removed from the glovebox. The reaction mixture was then stirred at $110{ }^{\circ} \mathrm{C}$ in a silicone oil bath for $3 \mathrm{~h}$, during which time a black precipitate formed. Upon cooling to room temperature, the microwave vial was opened and the precipitate was isolated by filtration, washed with $\mathrm{H}_{2} \mathrm{O}(30 \mathrm{~mL})$, and stirred in conc. aqueous hydrochloric acid $(10 \mathrm{~mL})$ for $2 \mathrm{~h}$. The remaining black polymer was filtered, washed with $\mathrm{H}_{2} \mathrm{O}(30 \mathrm{~mL})$ and $\mathrm{MeOH}$ $(30 \mathrm{~mL})$, dried over dynamic vacuum, and activated under a stream of nitrogen at $150{ }^{\circ} \mathrm{C}$ for $12 \mathrm{~h}$ to afford $\mathbf{A}_{2} \mathbf{C}_{1}(80 \mathrm{mg}$, 97\%).

Representative Procedure for the Metallation of Polymers. POP $L a A_{2} B_{1} . \mathbf{A}_{2} \mathbf{B}_{1}(100 \mathrm{mg})$ was added to a solution of $\mathrm{La}(\mathrm{acac}){ }_{3} \cdot \mathrm{H}_{2} \mathrm{O}(260 \mathrm{mg}, 0.57 \mathrm{mmol})$ in $\mathrm{MeOH}(10$ $\mathrm{mL}$ ) and stirred at $50{ }^{\circ} \mathrm{C}$ for $18 \mathrm{~h}$. The suspension was filtered and the solid polymer was extracted for $12 \mathrm{~h}$ with $\mathrm{MeOH}$ using a Soxhlet apparatus. The remaining material was filtered and activated under a stream of nitrogen at $150{ }^{\circ} \mathrm{C}$ for $12 \mathrm{~h}$.

Representative Procedure for the Methanolysis of $p$ nitrophenyl Dimethyl Phosphate (PNPDMP) by La(catecholate)-Functionalized POPs under Shaking Conditions. On the benchtop, a 2 dram vial was charged with PNPDMP (19 mg, $25 \mathrm{mM}$ ), La(catecholate)-functionalized POP catalyst ( $4 \mathrm{mg}$ for $\mathrm{LaA}_{2} \mathrm{C}_{1}, 6 \mathrm{~mol} \% \mathrm{La}^{\mathrm{III}}$ ), and methanol $(3 \mathrm{~mL})$. The reaction vial was sealed with a Teflon-lined cap and allowed to shake at $200 \mathrm{rpm}$ (see section S5 in the SI for a discussion on the importance of this protocol) and $60{ }^{\circ} \mathrm{C}$ in a Thermolyne Type 17600 aluminum heating block (Thermolyne, Dubuque, IA) mounted on a Thermolyne Type 65800 shaker (Thermolyne, Dubuque, IA). Periodically, the reaction vial was removed from the shaker, cooled down to below $50{ }^{\circ} \mathrm{C}$ with a quick spray of acetone $(\sim 5 \mathrm{~s})$ to prevent excessive $\mathrm{MeOH}$ evaporation, and quickly opened for aliquot $(100 \mu \mathrm{L})$ sampling before being put back on the shaker. The sampled aliquot was diluted with $\mathrm{MeOH}$ to $25 \mathrm{~mL}$ in a volumetric flask and analyzed by UV-vis spectroscopy. The conversion of PNPDMP as a function of reaction time was obtained by monitoring the increase of absorbance of $p$-nitrophenol at 311 nm.

Hydrolysis of $p$-Nitrophenyl Dimethyl Phosphate (PNPDMP) by $\mathrm{LaA}_{2} \mathrm{C}_{1}$ under Shaking Conditions. On the benchtop, PNPDMP (19 mg, $25 \mathrm{mM}), \mathrm{LaA}_{2} \mathbf{C}_{1}$ (4 mg, 6 $\left.\mathrm{mol} \% \mathrm{La}^{\mathrm{III}}\right)$ and 4-ethylmorpholine buffer solution (93 mM, 30 vol \% EtOH, pH 10, $3 \mathrm{~mL})^{34}$ were placed in a 2 dram vial. The reaction vial was sealed with a Teflon-lined cap and allowed to shake at $200 \mathrm{rpm}$ and $60{ }^{\circ} \mathrm{C}$ in a Thermolyne Type 17600 aluminum heating block (Thermolyne, Dubuque, IA) mounted on a Thermolyne Type 65800 shaker (Thermolyne, Dubuque, IA). Periodically, the reaction vial was removed from the shaker and quickly opened for aliquot $(100 \mu \mathrm{L})$ sampling before being put back on the shaker. The sampled aliquot was diluted with the buffer solution to $25 \mathrm{~mL}$ in a volumetric flask and analyzed by UV-vis spectroscopy. The conversion of PNPDMP as a function of reaction time was obtained by monitoring the increase of absorbance of the $p$-nitrophenolate ion at $406 \mathrm{~nm}$.

\section{RESULTS AND DISCUSSION}

In exploring the use of La-functionalized catPOPs for phosphate ester hydrolysis, we wanted to investigate how the substrate accessibility of the micropore reaction environment, and thus its catalytic activity, can be tuned by incorporating different organic linkers. Previously, ${ }^{21}$ we have demonstrated that the copolymerization of an orthoester-protected 1,4diethynyl-2,3-dihydroxybenzene ${ }^{35}$ (see Scheme S1 in the SI for its synthesis) with a $T_{\mathrm{d}}$-directing tetrakis(4-ethynyl)methane monomer $^{36}$ (see Scheme S2 in the SI for its synthesis) in different monomer ratios resulted in a family of porous polymers with tunable surface areas and pore size distributions. One member of this family $\left(\mathbf{A}_{2} \mathbf{B}_{1}\right.$, Scheme $1, \mathrm{R}=$ Carbon, $)$ was then metallated with divalent metals that readily bind small molecules such as $\mathrm{H}_{2} \cdot{ }^{21}$ For the degradation of large phosphate ester substrates, we hypothesized that using the larger $T_{\mathrm{d}^{-}}$ 
Table 1. Pore, Surface, and Catalytic Properties of Catechol-Containing POPs

\begin{tabular}{|c|c|c|c|c|c|c|c|c|}
\hline entry & POP & $\begin{array}{l}\text { BET surface } \\
\text { area }\left(\mathrm{m}^{2} / \mathrm{g}\right)\end{array}$ & $\begin{array}{l}\text { theoretical metal } \\
\text { loading (wt \%) }\end{array}$ & $\begin{array}{c}\text { actual metal } \\
\text { loading (wt \%) }\end{array}$ & $\begin{array}{l}\text { total pore } \\
\text { volume } \\
\left(\mathrm{cm}^{3} / \mathrm{g}\right)\end{array}$ & $\begin{array}{l}\text { dominant pore } \\
\text { diameter }(\AA)\end{array}$ & $\begin{array}{l}\text { observed initial } \\
\text { rate }\left(\mathrm{M} \mathrm{s}^{-1}\right)^{a, b}\end{array}$ & $\begin{array}{l}\text { relative initial rate vs } \\
\text { uncatalyzed reaction }\end{array}$ \\
\hline 1 & $A_{2} B_{1}$ & 1050 & & & 0.51 & $12 \pm 2$ & & \\
\hline 2 & $\mathrm{LaA}_{2} \mathrm{~B}_{1}$ & 265 & 23 & 22 & 0.09 & $11 \pm 2$ & $7.0 \times 10^{-7}$ & 41 \\
\hline 3 & $\mathrm{~A}_{2} \mathrm{C}_{1}$ & 1165 & & & 0.59 & $13 \pm 2$ & & \\
\hline 4 & $\mathrm{LaA}_{2} \mathrm{C}_{1}$ & 650 & 20 & 16 & 0.28 & $11 \pm 2$ & $1.7 \times 10^{-6}$ & 100 \\
\hline
\end{tabular}

${ }^{a}$ Reaction conditions: PNPDMP $(25 \mathrm{mM}),\left[\mathrm{La}{ }^{\mathrm{III}}\right](1.5 \mathrm{mM}, 6 \mathrm{~mol} \%), \mathrm{MeOH}, 60{ }^{\circ} \mathrm{C} .{ }^{b}$ Initial rates were measured up to $10 \%$ conversion and corrected against background reactions. ${ }^{c}$ Reaction conditions for the uncatalyzed reaction: PNPDMP $(25 \mathrm{mM}), \mathrm{MeOH}, 60{ }^{\circ} \mathrm{C}$. Initial rate was also measured up to $10 \%$ conversion.

directing tetrakis(4-ethynyl)adamantyl monomer ${ }^{37}$ (Scheme 1, $\mathrm{R}$ = adamantyl; see Scheme S3 in the SI for its synthesis) would result in a POP with higher surface area, more accessible pores, and thus increased catalytic activity. In addition, the more hydrophobic adamantyl node could further enhance the solvophobic encapsulation of the hydrophobic PNPDMP substrate in polar media and increase the catalysis rate. ${ }^{19,24}$

As shown in Table 1 , polymer $\mathbf{A}_{2} \mathbf{C}_{\mathbf{1}}$ has a BET surface area that is about $10 \%$ higher than that for $\mathbf{A}_{2} \mathbf{B}_{1}$ (1165 vs $1050 \mathrm{~m}^{2}$ ) g, respectively; see also Figure 1). Both catPOPs were smoothly

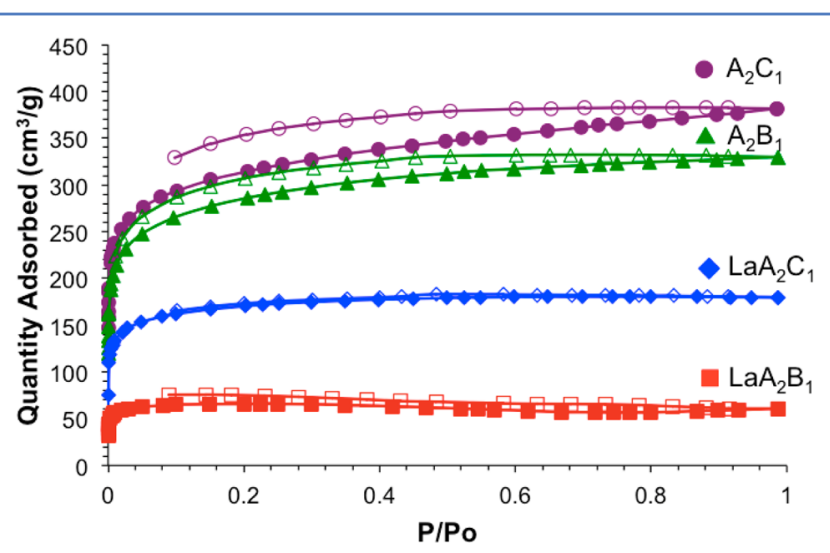

Figure 1. Nitrogen isotherms measured at $77 \mathrm{~K}$ for polymers $\mathbf{A}_{2} \mathbf{C}_{1}$ (purple cirlces), $\mathbf{A}_{2} \mathbf{B}_{1}$ (green triangles), $\mathbf{L a A}_{2} \mathbf{C}_{1}$ (blue diamonds), and $\mathbf{L a A}_{2} \mathbf{B}_{1}$ (red squares). Closed symbols, adsorption; open symbols, desorption.

metallated in the presence of excess $\mathrm{La}(\mathrm{acac})_{3}$ to afford the corresponding La-functionalized catPOPs with close to a 1:1 catechol:metal stoichiometry. Although the nonmettalated POPs show a small difference in BET surface areas, $\mathrm{LaA}_{\mathbf{2}} \mathbf{C}_{\mathbf{1}}$ shows a surprisingly $\sim 2.5$-fold higher surface area over $\mathbf{L a A}_{2} \mathbf{B}_{1}$ $\left(650 \mathrm{vs} 265 \mathrm{~m}^{2} / \mathrm{g}\right)$ and a 3 -fold higher methanol uptake at 0.80 $P_{\text {(partial) }} / P_{\text {(relative) }}$ (Figure $\mathrm{S} 18$ in SI). Given that the pore diameters are similar for both materials, (Figures S14 and S15 in the SI, pore size distributions were calculated using nitrogen and argon measurements respectively) the larger surface area and methanol-uptake capacity for $\mathrm{LaA}_{2} \mathbf{C}_{1}$ indicate its greater pore accessibility, which should make it a better catalyst for the solvolysis/hydrolysis of a phosphate triester.

The methanolysis of $p$-nitrophenyl dimethyl phosphate (PNPDMP), a toxic pesticide and simulant for chemical warfare agents, ${ }^{38}$ is enhanced by both $\mathbf{L a A}_{2} \mathbf{B}_{1}$ and $\mathbf{L a A}_{2} \mathbf{C}_{1}$ (Figure 2). As expected, significantly enhanced activity was observed with POP $\mathrm{LaA}_{2} \mathrm{C}_{1}$, which has much higher specific surface area than $\operatorname{LaA}_{2} \mathbf{B}_{1}$ : the initial methanolysis rate for the former is $\sim 2.5$ fold faster than that for the latter (Table 2). Surprisingly, a significant amount of $\mathrm{La}^{\mathrm{III}}$ (10\% of the overall

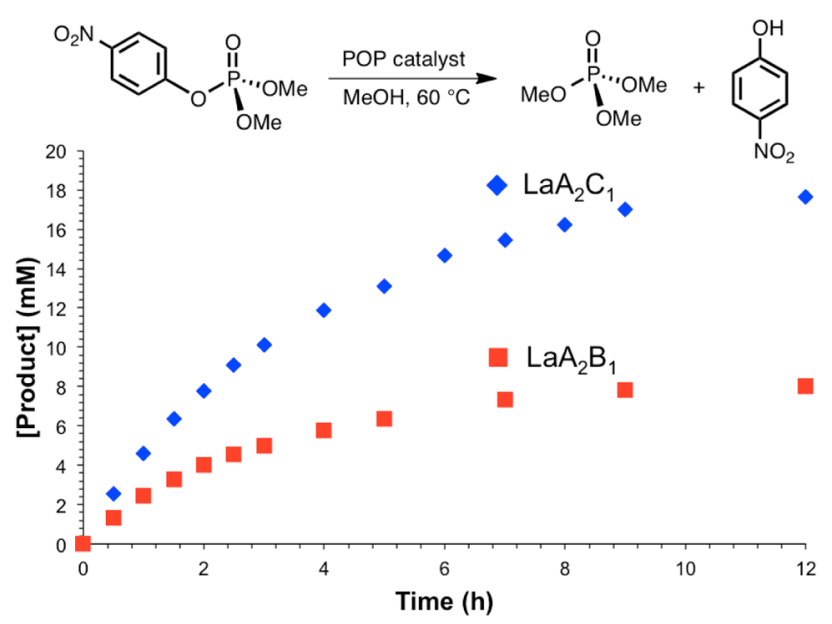

Figure 2. Reaction profiles for the methanolysis of PNPDMP in the presence of $6 \mathrm{~mol} \%$ of either $\mathbf{L a A}_{2} \mathbf{C}_{1}$ (blue diamonds) or $\mathbf{L a A}_{2} \mathbf{B}_{1}$ (red squares).

Table 2. Observed Initial Rates in the Methanolysis of PNPDMP by $\mathrm{LaA}_{2} \mathrm{~B}_{1}$ and $\mathrm{LaA}_{2} \mathrm{C}_{1}$

$\begin{array}{ccccc}\text { catalyst }^{a} & \text { cycle } & \begin{array}{c}\text { observed initial rate } \\ \left(\mathrm{M} \mathrm{s}^{-1}\right)^{b}\end{array} & \begin{array}{c}\text { LaII } \\ \text { leaching } \\ (\%)^{c}\end{array} & \begin{array}{c}\text { relative rate vs uncat } \\ \text { reaction }\end{array} \\ \mathbf{L a A}_{2} \mathbf{B}_{1} & 1 & 7.0 \times 10^{-7} & 10.1 & 41 \\ \mathbf{L a A}_{2} \mathbf{C}_{1} & 1 & 1.7 \times 10^{-6} & 0.1 & 100 \\ & 2 & 7.1 \times 10^{-7} & 0.6 & 42 \\ & 3 & 2.9 \times 10^{-7} & 4.3 & 17 \\ & 4^{d} & 7.0 \times 10^{-8} & 1.4 & 4\end{array}$

${ }^{a}$ Reaction conditions: PNPDMP (25 mM), [La ${ }^{\mathrm{III}}$ ] $(1.5 \mathrm{mM}, 6 \mathrm{~mol} \%)$, $\mathrm{MeOH}, 60^{\circ} \mathrm{C} .{ }^{b}$ Initial rates were measured up to $10 \%$ conversion and corrected against background reactions. ${ }^{c}$ Percentage of the initial metal loading. ${ }^{d}$ After Soxhlet extraction with THF.

$\mathrm{La}^{\mathrm{III}}$ content as determined by ICP-OES analysis of the product solutions) leached from $\operatorname{LaA}_{2} \mathbf{B}_{1}$ during the reaction, in contrast to the negligible leaching in the case of $\mathbf{L a A}_{2} \mathbf{C}_{1}$ (Table 2). Although the BET-derived pore size distributions of these two materials are quite similar (Figures S14 and S15 in the SI), the leaching differences can be explained if the local environments around the $\mathrm{La}$ (catecholate) moieties are different enough to cause instability. Supporting this speculation is the observation that the acac counterion is not visible in the solid-state IR spectra of $\mathrm{LaA}_{2} \mathrm{~B}_{1}$, but is observable in that for $\mathrm{LaA}_{2} \mathrm{C}_{1}$ (see section $\mathrm{S} 13$ in the $\mathrm{SI}$ ).

The degree of $\mathrm{La}^{\mathrm{III}}$ leaching was further corroborated by monitoring the catalytic activities of the solution phases in the methanolysis of PNPDMP by $\mathbf{L a A}_{2} \mathbf{C}_{1}$ and $\mathbf{L a A}_{2} \mathbf{B}_{1}$. After each reaction reached $30 \%$ conversions $\left(\sim 2 \mathrm{~h}\right.$ for $\mathbf{L a A}_{2} \mathbf{C}_{1}$ and $\sim 3 \mathrm{~h}$ 
for $\mathbf{L a A}_{2} \mathbf{B}_{1}$ ), the POP particles were removed by filtering and the PNPDMP concentrations in the solutions were further monitored. The background-corrected rate of methanolysis is $\sim 1$.7-fold higher in the filtrate for $\operatorname{LaA}_{2} \mathbf{B}_{1}$ than that for $\mathbf{L a A}_{2} \mathbf{C}_{1}$ (Figure $\mathrm{S} 12$ in the $\mathrm{SI}$ ), which is consistent with the former containing a larger amount of leached $\mathrm{La}^{\mathrm{III}}$ ions. The activity in the filtrate is much less than that for an equivalent amount of $\mathrm{La}(\mathrm{acac})_{3}$ (see section S6 in the SI), suggesting that the leached $\mathrm{La}^{\mathrm{III}}$ is a much less-active form than $\mathrm{La}(\mathrm{acac})_{3}$ monomer.

Motivated by the promising catalytic activity of $\mathrm{LaA}_{2} \mathrm{C}_{1}$, we examined its recyclability in the methanolysis of PNPDMP (Table 2). Surprisingly, the initial methanolysis rate drops significantly with each cycle, even though little leaching of La ${ }^{\text {III }}$ is observed. This phenomenon can be attributed to a number of factors: (1) the substrate/products are retained in the pores during catalysis, thus blocking new substrate from entering; (2) the framework of the POP is degraded/relaxed, which inhibits substrate access to the catalytic sites; ${ }^{39}$ or (3) the encapsulated $\mathrm{La}$ (catecholate) moieties are degraded into less-active forms during catalysis.

To evaluate the possibility that substrate/products may be clogging the pores, $\mathbf{L a A}_{2} \mathbf{C}_{1}$ was Soxhlet-extracted with THF for $24 \mathrm{~h}$ after the third cycle. Surprisingly, evaluation of the filtrate by UV-vis spectroscopy revealed a significant amount of "adsorbed" PNPDMP substrate $(2.7 \mathrm{mg}$ from $6.6 \mathrm{mg}$ of isolated materials, or a 2.4 substrate:La molar ratio). While we cannot determine if the adsorbed substrate is bound to the oxophilic $\mathrm{La}^{\mathrm{III}}$ ion, its sequestration in the pores might be limiting transport between the pores and the external solution, thereby contributing to the reduction of catalytic activity. Unfortunately, the catalytic activity of the Soxhlet-extracted $\mathrm{LaA}_{2} \mathrm{C}_{1}$ did not improve, as the initial rate for the "fourth" cycle was only $4 \times$ faster than that for the uncatalyzed reaction.

To evaluate factors 2 and 3, we "aged" $\mathbf{L a A}_{2} \mathbf{C}_{1}$ in methanol at $60{ }^{\circ} \mathrm{C}$ and in the absence of PNPDMP for four days, and then remeasured its surface area by $\mathrm{N}_{2}$ gas adsorption (see Section S8 in the SI). To our surprise, the BET surface area greatly decreased $\left(650 \mathrm{~m}^{2} / \mathrm{g}\right.$ as-synthesized vs $180 \mathrm{~m}^{2} / \mathrm{g}$ aged, Figure 3 ). However, conducting the same aging experiment on the nonmetallated POP $\mathbf{A}_{2} \mathbf{C}_{1}$ produced no significant change in surface area $\left(1170 \mathrm{~m}^{2} / \mathrm{g}\right.$ as-synthesized vs $1080 \mathrm{~m}^{2} / \mathrm{g}$ aged). This result led us to conclude that the degradation of supported $\mathrm{La}$ (catecholate) moieties into less-active forms must be an important contributor to the successive decrease in catalysis rate. Although we do not know the exact nature of the

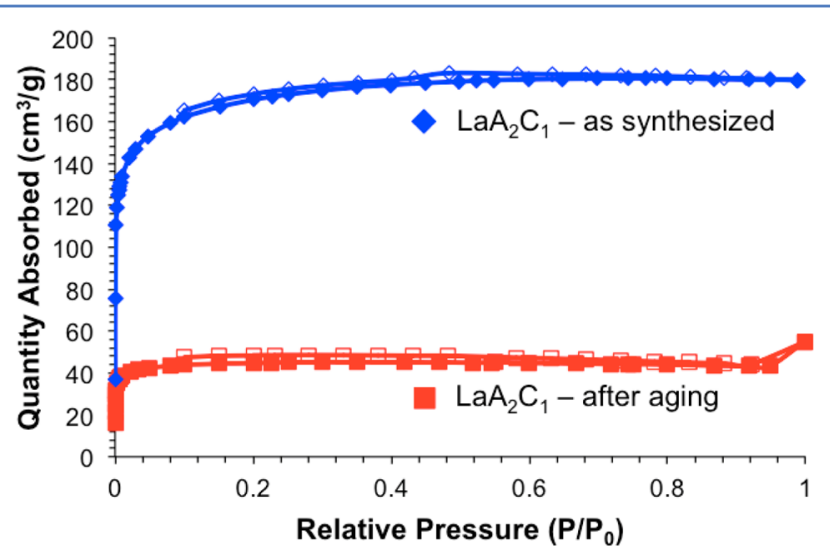

Figure 3. BET isotherms for as-synthesized $\mathrm{LaA}_{2} \mathrm{C}_{\mathbf{1}}$ (blue diamonds) and after aging (red squares) at $60{ }^{\circ} \mathrm{C}$ in methanol for four days. degradation products, it is conceivable that the $\mathrm{La}^{\mathrm{III}}$ ion could be cleaved from the catechol in the presence of $\mathrm{MeOH}$ to form less active species that are trapped in the micropores. Such an explanation is consistent with both the low La ${ }^{\mathrm{III}}$ leaching and the decrease in the surface area of the POP. Together with the build-up of substrate in the pores, these data indicate that the drop in catalytic activity after each cycle of methanolysis is due to a combination of $\mathrm{La}$ (catecholate) degradation as well as a decrease in transport through the pores of $\mathrm{LaA}_{2} \mathrm{C}_{1}$ because of substrate sequestration.

As both $\mathbf{A}_{2} \mathbf{C}_{1}$ and $\mathrm{LaA}_{2} \mathbf{C}_{1}$ can take up a significant amount of water vapor (see Figure S19 in SI, section 14), we hypothesize that $\mathrm{LaA}_{2} \mathrm{C}_{1}$ would be active in the hydrolysis of PNPDMP, which is a more practical route toward the destruction of nerve agents. ${ }^{40}$ Under $\mathrm{pH} 10$ buffered conditions and in 30 vol \% EtOH, which helps to solubilize the nerve agent simulant, the hydrolysis of PNPDMP in the presence of $\mathbf{L a A}_{2} \mathbf{C}_{1}$ is 12 times faster than the uncatalyzed reaction (Figure 4). In contrast to the catalyzed methanolysis of PNPDMP,

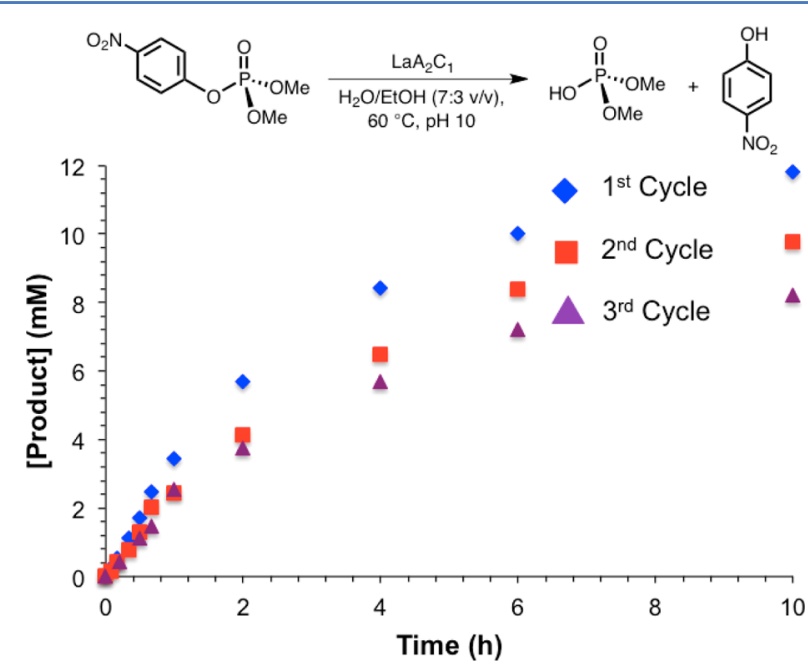

Figure 4. Reaction profiles for the first three hydrolysis cycles of PNPDMP in the presence of $6 \mathrm{~mol} \% \mathrm{LaA}_{2} \mathrm{C}_{1}$ in 4-ethyl morpholine buffer solution $(93 \mathrm{mM}, 30$ vol \% $\mathrm{EtOH}, \mathrm{pH} 10)$ using shaking conditions. First cycle, blue diamonds; second cycle, red squares; third cycle, purple triangles.

$\mathbf{L a A}_{2} \mathbf{C}_{1}$ retains significantly more catalytic activity over three cycles of hydrolysis: the initial rate only drops $40 \%$ after the first cycle and remains the same for the second and third cycles, showing good recyclability (Table 3 ). Soxhlet extraction of the $\mathbf{L a A}_{2} \mathbf{C}_{1}$ catalyst after each cycle revealed essentially no trapping

Table 3. Observed Initial Rates in the Hydrolysis of PNPDMP by $\mathrm{LaA}_{2} \mathrm{~B}_{1}$ and $\mathrm{LaA}_{2} \mathrm{C}_{1}$

$\begin{array}{ccccc}\text { catalyst }^{a} & \text { cycle } & \begin{array}{c}\text { observed rate } \\ \left(\mathrm{M} \mathrm{s}^{-1}\right)^{b}\end{array} & \begin{array}{c}\mathrm{La}^{\mathrm{III}} \text { leaching } \\ (\%)^{c}\end{array} & \begin{array}{c}\text { relative rate vs uncat } \\ \text { reaction }\end{array} \\ \mathrm{LaA}_{2} \mathbf{B}_{1} & 1 & 1.1 \times 10^{-6} & 0.1 & 12 \\ \mathrm{LaA}_{2} \mathrm{C}_{1} & 1 & 1.1 \times 10^{-6} & 0.1 & 12 \\ & 2 & 6.7 \times 10^{-7} & 0.1 & 7 \\ & 3 & 6.7 \times 10^{-7} & 0.2 & 7\end{array}$

${ }^{a}$ Reaction conditions: PNPDMP (25 mM), [La $\left.{ }^{\mathrm{III}}\right](1.5 \mathrm{mM}, 6 \mathrm{~mol} \%)$, 4-ethyl morpholine buffer solution (93 mM, 30 vol \% EtOH, $\mathrm{pH} 10$ ), $60{ }^{\circ} \mathrm{C}$. ${ }^{b}$ Initial rates were measured up to $10 \%$ conversion and corrected against background reactions. ${ }^{c}$ Percentage of the initial metal loading. 
of the substrate (see section S11 in the SI) and the amount of La leaching from $\mathrm{LaA}_{2} \mathrm{C}_{1}$ is again negligible. Together, these data suggest that under the basic buffered aqueous conditions, transport of the substrates through the cavities of $\mathbf{L a A}_{2} \mathbf{C}_{\mathbf{1}}$ is more facile and the $\mathrm{La}^{\mathrm{III}}$ sites are more stable against decomposition. The basic aqueous environment of the solution must have preferentially solubilized both the substrate and the acidic hydrolyzed products, keeping them from clogging the pores. Interestingly, PNPDMP hydrolysis by $\mathbf{L a A}_{2} \mathbf{B}_{1}$ under the same conditions yields similar turnover number with minimal leaching (Table 3).

\section{SUMMARY AND CONCLUSIONS}

In summary, two robust catechol-functionalized POPs with different $T_{\mathrm{d}}$-directing nodes can be synthesized and metallated with $\mathrm{La}^{\mathrm{III}}$ ions to afford catalytically active materials for the solvolytic and hydrolytic degradation of toxic organophosphates. Most notably, POP $\mathrm{LaA}_{2} \mathbf{C}_{1}$, with its higher accessible surface area, has significantly enhanced rates in the methanolytic decomposition of PNPDMP relative to the carbon-noded POP $\mathbf{L a A}_{2} \mathbf{B}_{1}$. Presumably, the higher specific surface area of the former increases its pore accessibility to the substrates and thus increases reaction rates. While there is minimal leaching of $\mathrm{La}^{\mathrm{III}}$ ions from the pores of POP $\mathrm{LaA}_{2} \mathrm{C}_{1}$, $\mathrm{La}$ (catecholate) degradation appears to be more significant in methanol; the significant decrease in methanolysis rate of $\mathbf{L a A}_{2} \mathbf{C}_{1}$ after each recycling experiment can, in part, be attributed to this problem. In addition, the choice of reaction media is an important consideration in the decomposition of PNPDMP: when the external medium does not solvate this substrate and its products well, preferential sequestration of these species inside the pores can clog them and significantly reduce catalysis. Clearly, one needs to keep in mind parameters such as pore accessibility and reaction media in the design of new catalyst materials.

\section{ASSOCIATED CONTENT}

\section{S Supporting Information}

Complete procedures for the synthesis of POP starting materials and characterization data (FTIR, ${ }^{1} \mathrm{H}$, and ${ }^{13} \mathrm{C}$ NMR), $\mathrm{H}_{2} \mathrm{O}$ and $\mathrm{MeOH}$ vapor isotherms and pore size distribution graphs, detailed procedures for catalysis, aging experiments, and the determination of nitrophenol extinction coefficient. This material is available free of charge via the Internet at http://pubs.acs.org.

\section{AUTHOR INFORMATION}

\section{Corresponding Author}

*E-mail: o-farha@northwestern.edu (O.K.F.); j-hupp@ northwestern.edu (J.T.H.); stn@northwestern.edu (S.T.N.).

Notes

The authors declare no competing financial interest.

\section{ACKNOWLEDGMENTS}

Financial support for this work is provided by DTRA (agreement HDTRA1-10-1-0023). Instruments in the Northwestern University Integrated Molecular Structure Education and Research Center (IMSERC) were purchased with grants from NSF-NSEC, NSF-MRSEC, Keck Foundation, the state of Illinois, and Northwestern University.

\section{REFERENCES}

(1) Weber, J.; Thomas, A. J. Am. Chem. Soc. 2008, 130, 6334-6335.

(2) Ben, T.; Ren, H.; Ma, S.; Cao, D.; Lan, J.; Jing, X.; Wang, W.; Xu, J.; Deng, F.; Simmons, J. M.; Qiu, S.; Zhu, G. Angew. Chem., Int. Ed. 2009, 48, 9457-9460.

(3) Chen, Q.; Luo, M.; Hammershøj, P.; Zhou, D.; Han, Y.; Laursen, B. W.; Yan, C.-G.; Han, B.-H. J. Am. Chem. Soc. 2012, 134, 60846087.

(4) Cooper, A. I. Adv. Mater. 2009, 21, 1291-1295.

(5) Yuan, D.; Lu, W.; Zhao, D.; Zhou, H.-C. Adv. Mater. 2011, 23, 3723-3725.

(6) Rabbani, M. G.; El-Kaderi, H. M. Chem. Mater. 2011, 23, 16501653.

(7) Hauser, B. G.; Farha, O. K.; Exley, J.; Hupp, J. T. Chem. Mater. 2012, 25, 12-16.

(8) Farha, O. K.; Spokoyny, A. M.; Hauser, B. G.; Bae, Y.-S.; Brown, S. E.; Snurr, R. Q.; Mirkin, C. A.; Hupp, J. T. Chem. Mater. 2009, 21, 3033-3035.

(9) McKeown, N. B.; Budd, P. M. Chem. Soc. Rev. 2006, 35, 675683.

(10) Rabbani, M. G.; El-Kaderi, H. M. Chem. Mater. 2012, 24, 15111517.

(11) Peterson, G. W; Farha, O. K; Schindler, B.; Jones, P.; Mahle, J.; Hupp, J. T J. Porous Mater. 2012, 19, 261-266.

(12) Mackintosh, H. J.; Budd, P. M.; McKeown, N. B. J. Mater. Chem. 2008, 18, 573-578.

(13) Shultz, A. M.; Farha, O. K.; Hupp, J. T.; Nguyen, S. T. Chem. Sci. 2011, 2, 686-689.

(14) Zhang, Y.; Riduan, S. N. Chem. Soc. Rev. 2012, 41, 2083-2094.

(15) Xie, Z.; Wang, C.; deKrafft, K. E.; Lin, W. J. Am. Chem. Soc. 2011, 133, 2056-2059.

(16) Jiang, J.-X.; Wang, C.; Laybourn, A.; Hasell, T.; Clowes, R.; Khimyak, Y. Z.; Xiao, J.; Higgins, S. J.; Adams, D. J.; Cooper, A. I. Angew. Chem., Int. Ed. 2011, 50, 1072-1075.

(17) Kaur, P.; Hupp, J. T.; Nguyen, S. T. ACS Catal. 2011, 1, 819835.

(18) Shultz, A. M.; Farha, O. K.; Hupp, J. T.; Nguyen, S. T. J. Am. Chem. Soc. 2009, 131, 4204-4205.

(19) Kang, B.; Kurutz, J. W.; Youm, K.-T.; Totten, R. K.; Hupp, J. T.; Nguyen, S. T. Chem. Sci. 2012, 3, 1938-1944.

(20) Wang, J.-L.; Wang, C.; deKrafft, K. E.; Lin, W. ACS Catal. 2012, 2, 417-424.

(21) Weston, M. H.; Farha, O. K.; Hauser, B. G.; Hupp, J. T.; Nguyen, S. T. Chem. Mater. 2012, 24, 1292-1296.

(22) Weston, M. H.; Peterson, G. W.; Browe, M. A.; Jones, P.; Farha, O. K.; Hupp, J. T.; Nguyen, S. T. Chem. Commun. 2013, 49, 29952997.

(23) Pierpont, C. G.; Lange, C. Prog. Inorg. Chem. 2007, 41, 331442.

(24) Totten, R. K.; Ryan, P.; Kang, B.; Lee, S. J.; Broadbelt, L. J.; Snurr, R. Q.; Hupp, J. T.; Nguyen, S. T. Chem. Commun. 2012, 48, 4178-4180.

(25) We note that Cohen and coworkers have incorporated protected-catechol struts into a derivative of UMCM-1 de novo, removed the protecting groups, and then metallated the free catechol groups with $\mathrm{Fe}(\mathrm{II})$. However, the metallated MOF was not demonstrated for catalytic capability. See: Tanabe, K. K.; Allen, C. A.; Cohen, S. M. Angew. Chem., Int. Ed. 2010, 49, 9730-9733.

(26) Parallel work using porous organic polymer (POPs) decorated with catechol groups as supports for unsaturated metal coordination environment with applications in catalysis have been published: (a) Tanabe, K. K.; Siladke, N. A.; Broderick, E. M.; Kobayashi, T.; Goldston, J. F.; Weston, M. H.; Farha, O. K.; Hupp, J. T.; Pruski, M.; Mader, E. A.; Johnson, M. J. A.; Nguyen, S. T. Chem. Sci. 2013, 4, 2483-2489. (b) Kraft, S. J.; Sánchez, R. H.; Hock, A. S. ACS Catal. 2013, 3, 826-830.

(27) Shibasaki, M.; Yoshikawa, N. Chem. Rev. 2002, 102, 2187-2210.

(28) Franklin, S. J. Curr. Opin. Chem. Biol. 2001, 5, 201-208. 
(29) Melnychuk, S. A.; Neverov, A. A.; Brown, R. S. Angew. Chem., Int. Ed. 2006, 45, 1767-1770.

(30) Tsang, J. S.; Neverov, A. A.; Brown, R. S. J. Am. Chem. Soc. 2003, 125, 7602-7607.

(31) Tsang, J. S. W.; Neverov, A. A.; Brown, R. S. Org. Biomol. Chem. 2004, 2, 3457-3463.

(32) Weibel, N.; Błaszczyk, A.; von Hänisch, C.; Mayor, M.; Pobelov, I.; Wandlowski, T.; Chen, F.; Tao, N. Eur. J. Org. Chem. 2008, 136149.

(33) Galoppini, E.; Gilardi, R. Chem. Commun. 1999, 173-174.

(34) Klinkel, K. L.; Kiemele, L. A.; Gin, D. L.; Hagadorn, J. R. Chem. Commun. 2006, 2919-2921.

(35) This compound was synthesized from commercially available 1,2-dimethoxybenzene ( 6 steps, $24 \%$ overall yield).

(36) This compound was synthesized from commercially available tetraphenylmethane ( 3 steps, $41 \%$ overall yield).

(37) This compound was synthesized from commercially available 1bromoadamantane (4 steps, $50 \%$ overall yield).

(38) Edwards, D. R.; Liu, C. T.; Garrett, G. E.; Neverov, A. A.; Brown, R. S. J. Am. Chem. Soc. 2009, 131, 13738-13748.

(39) Pandey, P.; Katsoulidis, A. P.; Eryazici, I.; Wu, Y.; Kanatzidis, M. G.; Nguyen, S. T. Chem. Mater. 2010, 22, 4974-4979.

(40) Smith, B. M. Chem. Soc. Rev. 2008, 37, 470-478. 